\title{
Pulmonary hypertension in scimitar syndrome in infancy
}

\author{
SHEILA G HAWORTH, URSULA SAUER, KONRAD BÜHLMEYER \\ From the Department of Paediatric Cardiology, Institute of Child Health, London; and Deutsches Herzzentrum, \\ Munich, Germany
}

SUMMARY Four infants with the scimitar syndrome presented with failure to thrive, cardiac failure, and pulmonary hypertension. In all cases systemic arteries arose from the upper abdominal aorta to perfuse the lower part of the right lung, and a large unobstructed anomalous pulmonary vein drained venous blood from almost the entire right lung to the inferior vena cava. An additional small pulmonary vein joined the inferior vena cava or right atrium and in three of the four cases angiography showed intrapulmonary connections between the two anomalous veins. At necropsy, in all four cases the right lung was hypoplastic. The bronchi were abnormal in size or number in three cases, but there was no sequestrated tissue. Microscopical examination showed normal peripheral airway and alveolar development. The pulmonary arterial branching pattern was deficient in three patients. Postmortem arteriography, dissection, and microscopical studies showed that in areas of lung not perfused by branches of the right pulmonary artery the systemic arteries anastomosed with intrapulmonary arteries to distribute blood to a dilated capillary bed. In all tissue examined arterial medial thickness was increased in both lungs while vein wall thickness was normal. For comparison a fifth patient, more typical of the syndrome, was included; this patient did not have pulmonary hypertension and died from septicaemia at 2 years of age.

Symptomatic infants with pulmonary hypertension probably have the most severe form of the scimitar syndrome. It is recommended that sick infants should have a two stage correction, systemic arteries being ligated at the first procedure and the anomalous vein being reimplanted in the left atrium at a second and later procedure, with closure of an atrial septal defect if present.

The scimitar syndrome consists of anomalous pulmonary venous drainage of the right lung into the inferior vena cava, hypoplasia of the right lung with dextroposition of the heart, hypoplasia or other malformations of the right pulmonary artery, and an anomalous systemic supply to the lower lobe of the right lung from the abdominal aorta or its main branches. ${ }^{1}$ Abnormal lobation and bronchial abnormalities are also described. The syndrome may be suggested by the scimitar-shaped shadow of the anomalous pulmonary vein along the right border of the heart on the chest $x$-ray film. Many patients have no symptoms throughout childhood. Only about one third of cases has been diagnosed in the paediatric age group, usually because of respiratory tract infections. ${ }^{2}$ Pulmonary hypertension is unusual.

Presentation in infancy is rare. Mortensson and

SGH is supported by the British Heart Foundation.

Accepted for publication 26 April 1983
Lundström ${ }^{3}$ described a baby who presented in cardiac failure at 9 days of age; the entire right lung was supplied by arteries which arose from the descending thoracic aorta. Park ${ }^{4}$ reported the condition at necropsy in a $2 \frac{1}{2}$ month old infant. Kuiper-Oosterwal and Moulaert ${ }^{2}$ described two infants who presented during the first two months of life with dyspnoea, neither of whom was said to have had pulmonary hypertension. By contrast, in 1976 Dupuis and his colleagues reported to the Association of European Paediatric Cardiologists that severe pulmonary hypertension was a constant feature in symptomatic infants with the scimitar syndrome.

This presentation describes the clinical, haemodynamic, and angiographic findings and the structural changes in the lungs of four infants who died with the scimitar syndrome, all of whom had pulmonary hypertension. For comparison, the findings are also presented in an older child who died 
Table Clinical data

\begin{tabular}{|c|c|c|c|c|c|c|c|c|}
\hline $\begin{array}{l}\text { Case } \\
\text { No. }\end{array}$ & $\begin{array}{l}\text { Age at } \\
\text { presentation } \\
\text { (mth) }\end{array}$ & Presentation & $\begin{array}{l}\text { Age at cardiac } \\
\text { catheterisation } \\
\text { (mth) }\end{array}$ & $\begin{array}{l}P A P \\
(\operatorname{mmH} H)\end{array}$ & $\underset{(\operatorname{man} H g)}{S A P / L V P}$ & $R p a$ & $\frac{Q p}{\left(l m^{2}\right)}$ & $Q p: Q s$ \\
\hline 1 & 1.5 & \multirow{4}{*}{$\begin{array}{l}\text { Failure to thrive and } \\
\text { cardiac failure } \\
\text { Faihure to thrive, } \\
\text { cardiac failure, cyanosis } \\
\text { Failure to thrive, } \\
\text { cyanosis } \\
\text { Failure to thrive } \\
\text { Murmur }\end{array}$} & 2 & $60 / 20$ & $70 / 12$ & 2.8 & $8 \cdot 3$ & - \\
\hline 2 & 2.5 & & 3 & $85 / 45$ & $85 / 45$ & $11 \cdot 1$ & 5.7 & 2.4 \\
\hline 3 & 4 & & $41 / 2$ & $73 / 26$ & $75 / 6$ & 12 & 3.4 & 1.5 \\
\hline $\begin{array}{l}4 \\
5\end{array}$ & $\begin{array}{r}3 \\
10\end{array}$ & & $\begin{array}{r}3 \\
18\end{array}$ & $\begin{array}{l}80 / 37 \\
25 / 10\end{array}$ & $\begin{array}{l}74 / 37 \\
85 / 65\end{array}$ & $\begin{array}{l}7 \\
1 \cdot 2\end{array}$ & $5 \cdot 2$ & $\begin{array}{l}2.4 \\
1.3\end{array}$ \\
\hline
\end{tabular}

Abbreviations; LVP, left ventricular pressure; PAP, pulmonary arterial pressure; Qp, pulmonary blood flow; Qp:Qs, pulmonary:systemic blood flow; Rpa, pulmonary arteriolar resistance.

at 2 years 4 months and who did not have pulmonary hypertension.

\section{Case reports}

Four children were symptomatic during the first six months of life (Table). All had failed to thrive, and two children presented in cardiac failure during the first three months. In the fifth child a murmur was heard at a routine examination at 10 months of age, but she remained well until she had meningitis and developed septicaemia from which she died at the age of 2 years and 4 months. In all five cases the $Q R S$ axis on the electrocardiogram suggested malposition of the heart in that there were deep Q waves in leads I and II and $R$ waves of large amplitude in all the standard limb leads. In cases 1 to 4 there were signs of right ventricular hypertrophy. In all five patients the chest radiograph showed a shift of the heart and mediastinum to the right and an increase in pulmonary vascular markings in the left lung (Fig. 1). In addition, in case 2 there were slight malformations of the ribs on the left side. In case 3 a scimitar shadow was seen, the right upper lobe appeared hypertranslucent and the lower lobe showed an increase in pulmonary vascular markings. In the other four cases the displacement of the heart to the right obscured the view of the anomalous pulmonary vein. In all four infants cardiac catheterisation studies indicated pulmonary hypertension, the systolic pulmonary and systemic arterial pressures being similar (Table). The pulmonary arteriolar resistance was $2.8 \mathrm{units} / \mathrm{m}^{2}$ in case 1 and greater than 7 units in the other three infants. In case 5 the pulmonary arterial pressure was normal. The cardiac catheterisation study also showed a small right to left shunt at atrial level in cases 3 and 4 . Case 3 had a small ventricular septal defect and case 4 a small persistent ductus arteriosus which could not be detected by oximetry. Four patients (cases 2 to 5 ) had either bronchographic studies or a bronchoscopy or both (see below).

Three infants had an operation, one infant deterior-

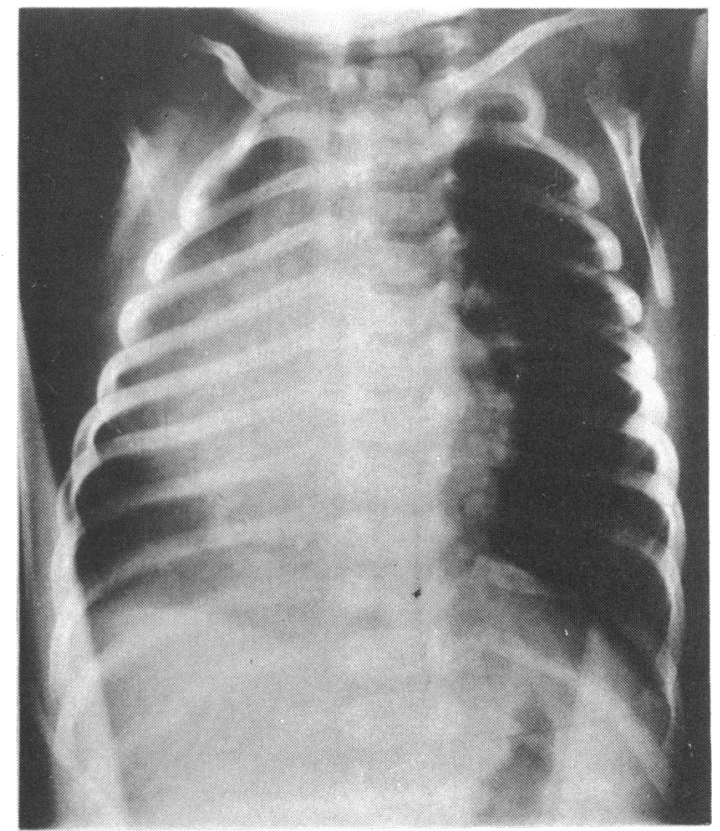

Fig. 1 Chest radiograph of case 2, showing displacement of the heart and mediastivim to the right.

ated suddenly and died before operation could be performed and the older patient died of an intercurrent infection. At operation none of the three infants had a definitive right lower lobe. In cases 1 and 2 ligation of a large anomalous pulmonary vein connected to the inferior vena cava produced massive intrapulmonary haemorrhage which necessitated a pneumonectomy. After operation both patients had episodes of cyanosis and bradycardia. Case 1 died five days and case 2 one month after operation. In case 2 , two postoperative cardiac catheterisation studies showed a pulmonary arterial pressure similar to the systemic arterial pressure, $75 / 35 \mathrm{mmHg}$ and $76 / 55 \mathrm{mmHg}$, respectively. The infant continued to deteriorate and died with a staphylococcal pneumonia. In case 4 , the lower part of the right lung was resected, the anomalous systemic 


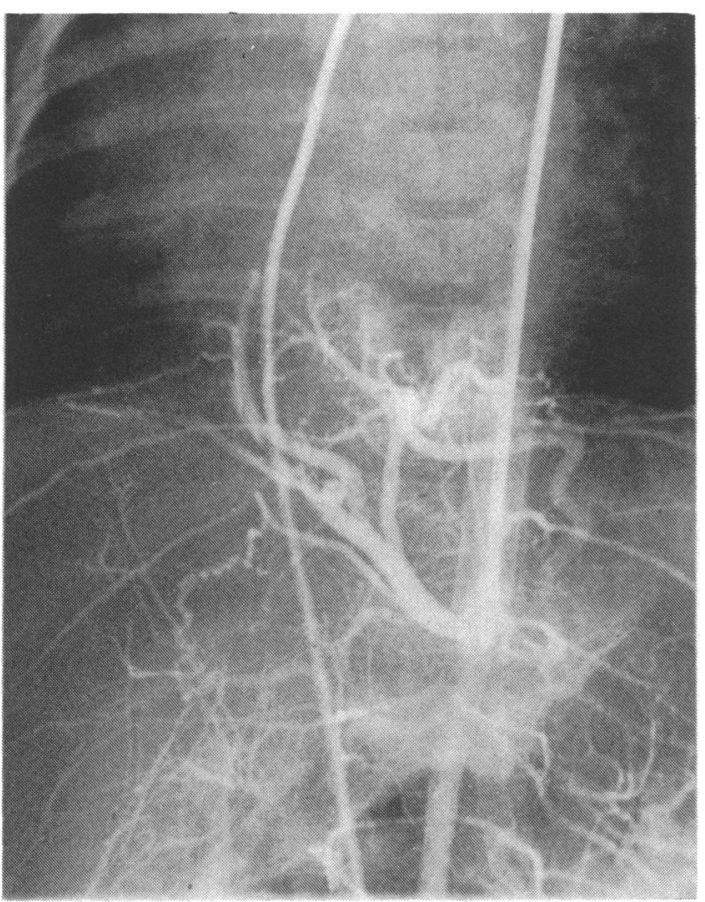

Fig. 2 Aortogram in case 2 showing systemic arteries perfusing the lower part of the right lung.

arteries were ligated and the large anomalous pulmonary vein was reimplanted into the left atrium. At a postoperative cardiac catheterisation study the pulmonary arterial pressure was similar to the systemic

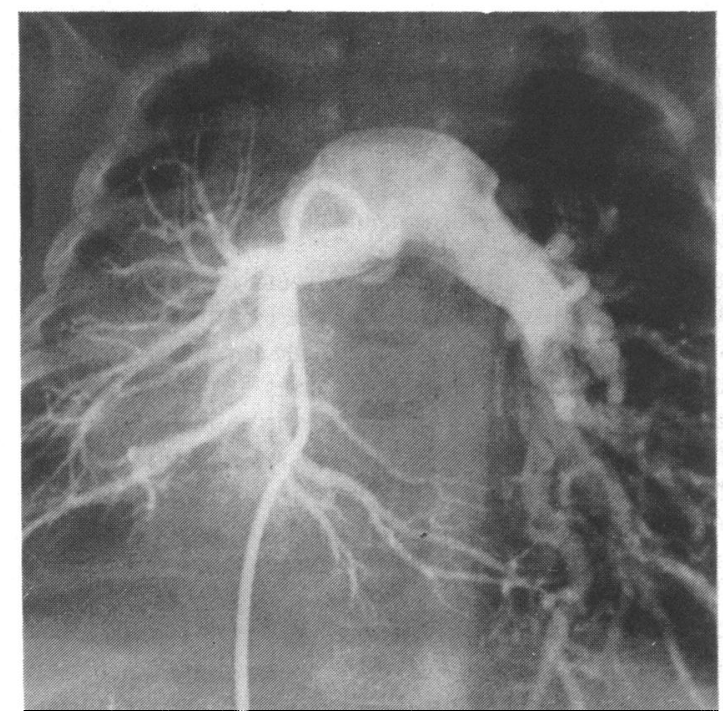

Fig. 3 Pulmonary angiogram in case 2, showing dilated, tortuous left intrapulmonary arteries and small right intrapulmonary arteries.

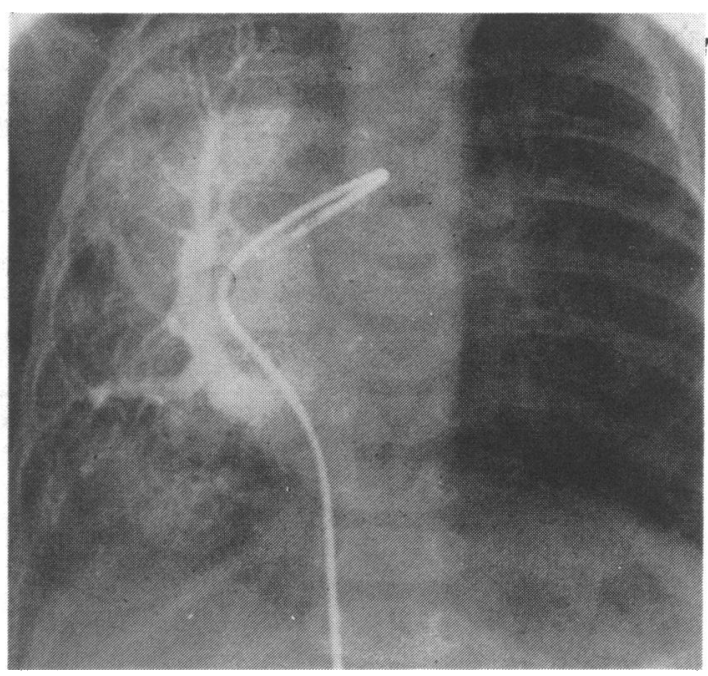

Fig. 4 Pulmonary angiogram in case 2 showing anomalous pulmonary vein.

arterial pressure, and the pulmonary venous return from the right lung could not be visualised, suggesting stenosis of the reimplanted right pulmonary vein. The baby died two months after operation with a severe infection.

\section{ANALYSIS OF ANGIOGRAPHIC STUDIES}

\section{Right lung}

In all five cases, one to three large arteries arose from the descending aorta, below the diaphragm, to supply

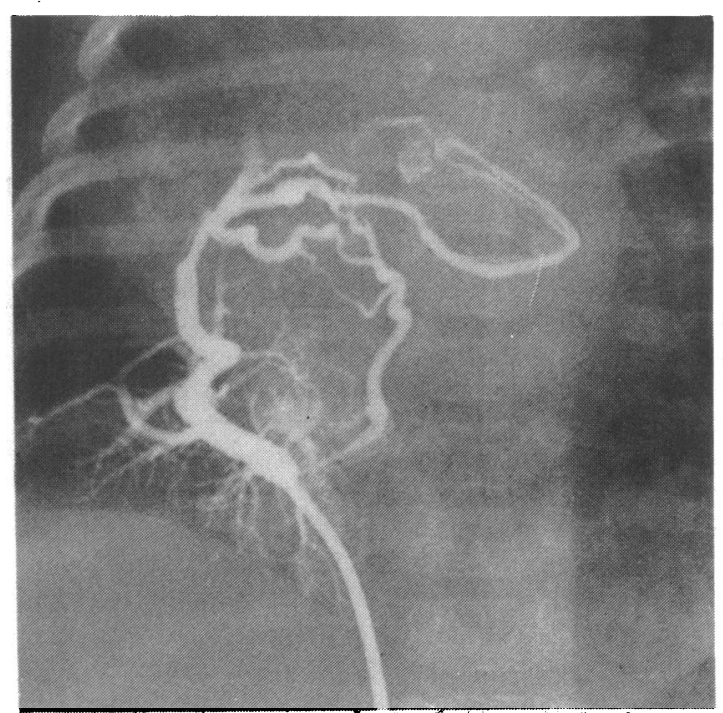

Fig. 5 Injection into the anomalous pulmonary vein in case 2, showing intrapulmonary connections with a second pulmonary vein which returns to the right atrium. 
the lower part of the right lung (Fig. 2). The pulmonary arterial branching pattern was abnormal in three cases. The anterobasal segmental artery to the lower lobe was absent in cases 1 and 2 , and in case 4 the upper lobe pulmonary artery was absent. The right pulmonary artery and its branches were smaller than normal in cases 1 to 4 (Fig. 3). In these four cases the pulmonary venous return from all parts of the right lung was totally or predominantly to a large vein, the scimitar vein, and thence to the inferior vena cava (Fig. 4). In cases 1 to 3 at least one small additional vein returned to the right atrium and connected within the lung with branches of the large anomalous pulmonary vein (Fig. 5).

In case 5 , the pulmonary arteries were dilated. The pulmonary venous blood from the middle and lower lobes and from part of the upper lobe returned to an anomalous vein which joined the inferior vena cava (Fig. 6). In addition, much of the upper lobe venous blood drained to the left atrium and there were large intrapulmonary connections between the veins draining to the inferior vena cava and the left atrium.

Connections between systemic and pulmonary arterial systems were not seen on angiography.

\section{Left lung}

In all five cases the pulmonary arterial branching pattern was normal and the venous blood drained entirely to the left atrium. The pulmonary arteries were dilated in all except case 3 and were tortuous in cases 1, 2, and 3 (Fig. 3).

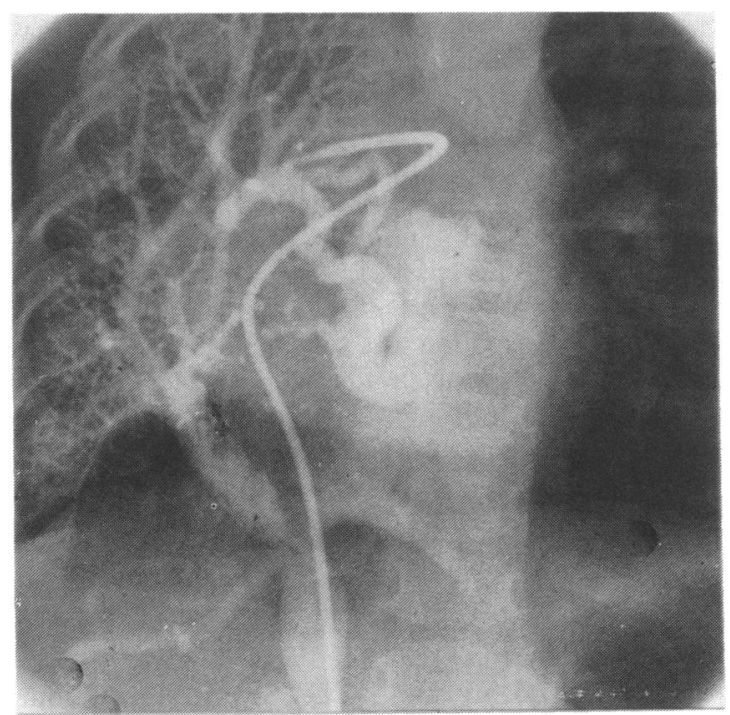

Fig. 6 Pulmonary angiogram in case 5 showing the large anomalous pulmonary vein anastomosing within the lung with a second pulmonary vein which drains to the left atrium.
BRONCHIAL ANATOMY IN RIGHT LUNG

The bronchi were normal in cases 3 and 5, as shown by bronchography in both and also by bronchoscopy in case 3 and postmortem dissection in case 5 . In case 2 the branching pattern was normal, but the right middle and lower "lobe" bronchi were narrow on bronchoscopic examination. The branching pattern was abnormal in cases 1 and 4 . In case 1 at necropsy the middle lobe bronchus could not be identified, the origin of the upper lobe bronchus had a lumen diameter of $1 \mathrm{~mm}$ and its branches were extremely small and the five lower lobe bronchi were also small. In case 4, at bronchography the upper lobe bronchus was not visualised and the middle lobe bronchus was distorted. At necropsy, the upper lobe bronchus consisted of a blind stump and there was no identifiable middle lobe bronchus. In all five cases that part of the right lung supplied by systemic arteries communicated with the rest of the tracheobronchial systems unlike a sequestrated segment.

\section{NECROPSY FINDINGS}

All cases, except case 3, were examined at necropsy; all the anomalous systemic arteries to the right lung arose from the descending aorta above the renal arteries and were friable and branched as they approached the lung; in case 1 as many as eight branches entered the lower half of the right lung. In cases 1,2 , and 4 the small right lung consisted of a single lobe. In these three cases a large anomalous pulmonary vein returned to the inferior vena cava. An additional small vein returned to the right atrium near the junction of the inferior vena cava in cases 1 and 2 , confirming the angiographic findings. In case 4 , an additional vein joined the inferior vena cava itself near its entrance to the right atrium. In cases 1 and 4 there were many adhesions between the lung and chest wall. In case 5, the right lung was divided normally into three lobes, but the upper lobe was small. An anomalous pulmonary vein from the lower lobe returned to the inferior vena cava and another vein returned normally to the left atrium. The right ventricle appeared hypertrophied in all four cases. In case 4 the reimplanted anomalous right pulmonary vein was stenosed, with a lumen diameter of $1 \mathrm{~mm}$ where it anastomosed with the left atrium. Cases 1 and 5 had a patent foramen ovale and case 4 had a secundum atrial septal defect measuring $1 \mathrm{~cm}$ in diameter. In cases 1,4 , and 5 the ductus arteriosus was closed and in case 2 it was patent, but the lumen diameter was less than $2 \mathrm{~mm}$. In case 5 necropsy showed endocarditis, meningitis, enterocolitis, and bronchopneumonia.

\section{INJECTION AND MICROSCOPICAL STUDIES}

The right lung of case 1 and the left lung of case 2 were injected with a barium sulphate gelatin mixture, 


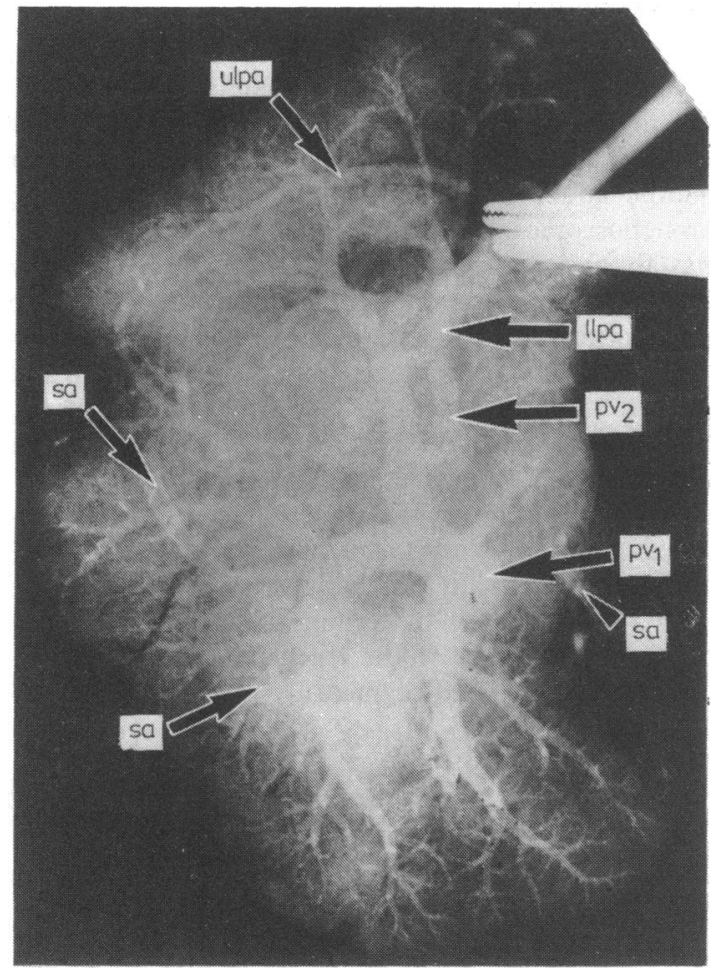

Fig. 7 Postmortem arteriogram of the right lung in case 1 . Injection cannula is in the pulmonary artery supplying the lower part of the right lung. $p v_{1}$, large anomalous pulmonary vein draining almost entire lung; $p v_{2}$, smaller second vein returning to right atrium; llpa, lower "lobe" pulmonary artery; sa, injected systemic arteries; ulpa, upper "lobe" pulmonary artery.

$x$-rayed, and dissected. ${ }^{56}$ Tissue from these lungs and from the resected and necropsy tissue of the other three cases was prepared for histological examination. Sections were stained with Miller's elastic stain counterstained with van Gieson's stain and with haematoxylin and eosin. Using both injected and uninjected tissue, quantitative morphometric techniques were used to analyse mean percentage pulmonary arterial medial thickness with respect to arterial size and the external diameter of arteries accompanying the terminal bronchioli, respiratory bronchioli, and alveolar ducts. ${ }^{5} 6$

\section{Case 1: Right lung}

Injection of each of the systemic arteries opacified a small volume of lung tissue and showed a background haze caused by filling of many small arteries. The pulmonary arterial branching pattern was abnormal (Fig. 7). Dissection and arteriography showed that the anterior, basal, cardiac, and apical regions of the lower "lobe" were not supplied by pulmonary arteries connected to the right pulmonary artery, but by sys- temic arteries which entered the lung to connect with intrapulmonary arteries. Three microscopical serial reconstructions showed that the peripheral pulmonary arteries were normally related to the airways and branched with them to supply the capillary bed in a normal manner. The right pulmonary artery branched at the hilum. One branch supplied the upper part of the lung. The other branch was equivalent to the posterobasal artery of the lower lobe in the normal lung, and it also gave rise to a lateral branch. The large anomalous vein drained the whole of the lower part and much of the upper part of the lung. A second, smaller vein drained the upper part of the lung (Fig. 7). Injection of the pulmonary arteries rapidly filled the two pulmonary veins with injection material and this is unusual using this technique. Examination of serial and random sections failed to show any precapillary arteriovenous connections. Throughout the lung, however, the alveolar capillaries were distended.

\section{Case 2: Left lung}

Postmortem arteriography confirmed the presence of a normal pulmonary arterial branching pattern seen at angiography. Measurement of the lumen diameter of the pre-acinar arteries showed that they were larger than normal for age.

\section{GENERAL MICROSCOPICAL FEATURES (CASES 1-5)}

In all the lung tissue examined from both lungs the small pre- and intra-acinar arteries, airways, and alveoli had a normal appearance, except in the first case, where the upper part of the right lung showed thickened alveolar septa, peribronchiolar fibrosis, and organised masses of cells within the alveoli, changes probably secondary to the hypoplasia of the bronchus supplying this area. The small pre- and intra-acinar arteries and veins were normally related to the airways. There were no findings to suggest dysplastic or sequestrated lung tissue. The arteries appeared abnormally thick walled.

Intimal proliferation was seen only in case 4 in the part of the right lung perfused by systemic arteries, and occurred in only a few vessels and was mild. Vein wall thickness appeared normal in all cases.

\section{QUANTITATIVE MORPHOLOGICAL STUDIES}

\section{Right lung}

Using uninjected tissue, percentage arterial muscularity was significantly increased in the three infants studied, but not in case 5 (Fig. 8a). In all the four cases examined tissue was analysed from the lower part of the lung supplied by anomalous systemic arteries. In cases 1 and 5 tissue from parts of the lung 

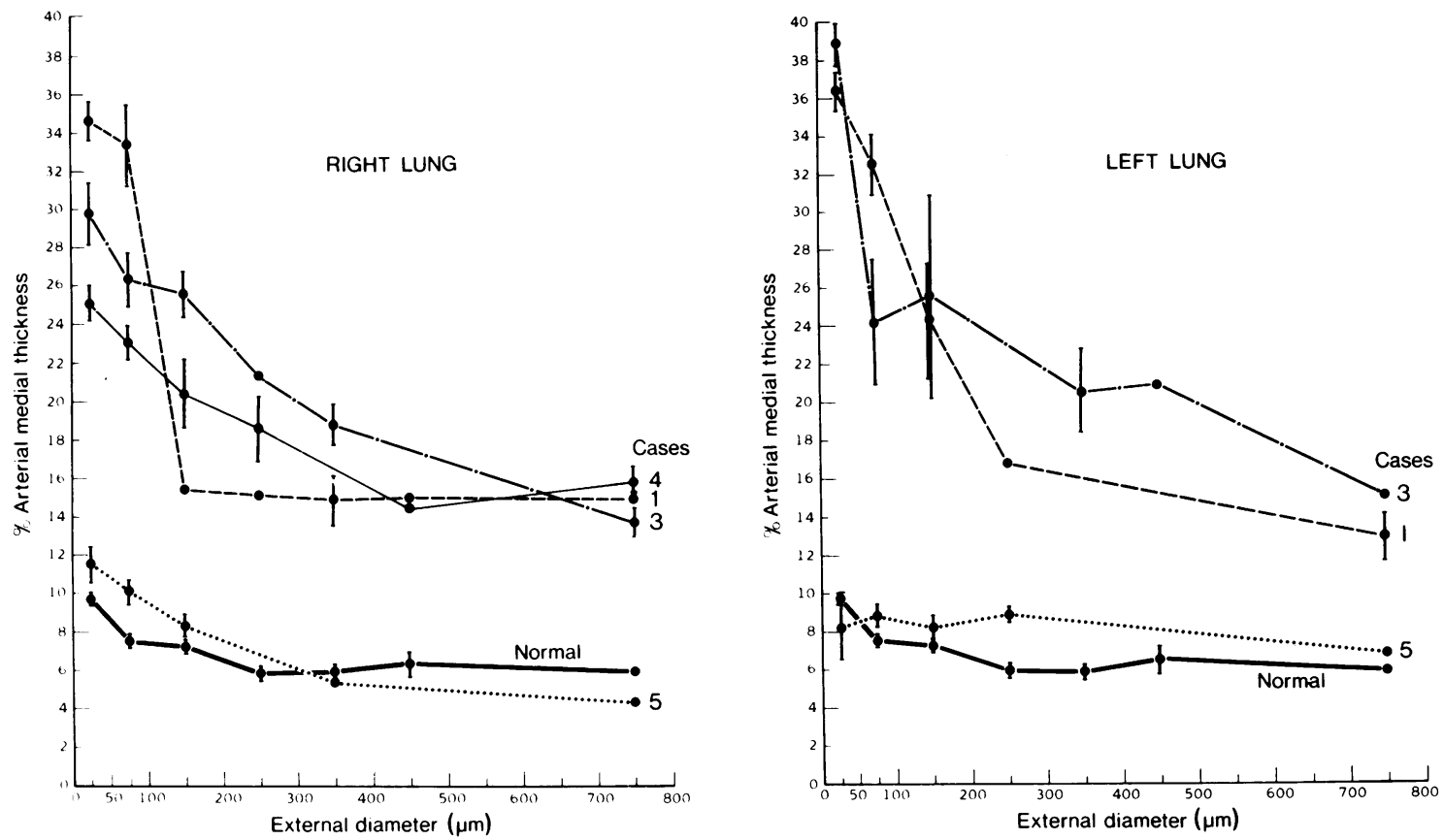

Fig. 8 (a) Right lung: percentage arterial medial thickness related to external diameter ( $\mu \mathrm{m})$ showing a significant increase in muscularity in cases 1, 3, and 4 as compared with the normal, and normal muscularity in case 5. (b) Left lung: percentage arterial medial thickness related to external diameter $(\mu \mathrm{m})$, showing a pronounced increase in muscularity in cases 1 and 3 , while muscularity is normal in case 5.

connected to pulmonary arteries was also analysed and the muscularity did not differ in parts of the lung having a different source of blood supply. The mean external diameter of arteries accompanying the intraacinar airways was normal in cases 1 and 4. The arteries were small in case 3 , being similar to the normal during the first day of life, and this case also showed the greatest increase in pulmonary arterial muscularity and the highest resistance in the group. In case 5, the intra-acinar arteries were dilated in lung tissue connected to the pulmonary arteries and were small in tissue connected to systemic arteries, being similar to the normal during the first few months of life.

\section{Left lung}

Using uninjected tissue, in the two infant cases studied (cases 1 and 3) muscularity was significantly greater than normal in arteries of all sizes (Fig. 8b). In case 2 studies on injected tissue showed an increase in muscularity only in arteries larger than $300 \mu \mathrm{m}$ in diameter, where percentage arterial medial thickness was $6 \%$ as compared with a normal value of $2 \%$. In the older case (case 5) muscularity was normal. In cases 1 and 5, the mean external diameter of intra-acinar arteries was normal for age. In case 3 the arteries in the left lung, like those in the right, were small for age. In case 2, the arteries were dilated with respect to age, by a factor of 3 .

\section{Discussion}

The scimitar syndrome comprises a wide range of abnormalities of the right lung in addition to the anomalous pulmonary venous connection to the inferior vena cava. In the present series the four children presenting in infancy showed most of the additional features, namely hypoplasia of the right lung with defective lobation and bronchial abnormalities, a systemic arterial supply to the lower part of the right lung and abnormalities of branching and size of the right pulmonary artery. The vascular rather than the airway manifestations of the syndrome dominated the clinical picture.

The abnormal lobation of the lung, the partial retention of a systemic arterial supply, and the persistent connection of a pulmonary vein to the splanchnic venous system suggests that lung development was impaired at an early stage during fetal life. In the normal fetus division of the lung buds into lobes is apparent at 20 to 30 days of gestation. ${ }^{7}$ At 50 days the lung ceases to be connected to segmental systemic arteries and is entirely and exclusively connected to the central pulmonary arteries. ${ }^{8}$ The intrapulmonary 
veins drain into the left atrium by the eleventh week of gestation.910 In the present series, the normal appearance of the peripheral arteries, veins, and airways suggests that subsequently fetal development proceeded normally, particularly after the 16th week of gestation, when pre-acinar arterial, venous, and airway branching is complete.

The scimitar syndrome is so called because on the chest radiograph the anomalous right pulmonary vein produces a shadow likened to a Turkish sword along the right border of the heart. ${ }^{1}$ Hypoplasia of the right lung, however, causes a shift of the heart and mediastinum to the right and may obscure the scimitar shadow, as occurred in four of the five cases in the present study. The diagnosis is most likely to be missed before cardiac catheterisation in young children in whom the scimitar shadow is obscured and the signs of a large left to right shunt suggest an intracardiac abnormality. At cardiac catheterisation the systemic arterial supply to the lower part of the right lung might suggest a sequestrated segment unless the pulmonary venous drainage is demonstrated.

One child in the series (case 5) had the typical clinical picture of the scimitar syndrome in that she had no symptoms in early childhood, the diagnosis was made incidentally, there was no clinical or pathological evidence of significant pulmonary hypertension, and the left to right shunt was small, $1 \cdot 2: 1$. By contrast, the four children presenting in infancy had severe pulmonary hypertension, an unusual finding in patients with the scimitar syndrome. In 1977, Honey11 collected from the published material eight cases in which the pulmonary arterial pressure exceeded $50 \mathrm{mmHg}$ and added one of his own. In four patients the presence of pulmonary hypertension was explained by associated anomalies such as a large ductus arteriosus or an atrioventricular canal or by obstruction of the anomalous vein. In four cases, however, there was no apparent explanation. Three of the patients were adult, but one patient presented at 7 months of age and died at $2 \frac{1}{2}$ years with severe pulmonary vascular obstructive disease including plexiform lesions in the left lung. In the present study also, associated intracardiac abnormalities, a secundum atrial septal defect in one case, and a small ventricular septal defect in another, are unlikely to have influenced the development of pulmonary hypertension. In addition, obstruction of the anomalous veins was not seen angiographically or at necropsy; and on microscopy pulmonary vein wall structure was normal.

In our study the young age of the patients with symptoms suggests that pulmonary hypertension might have been caused by failure of the pulmonary circulation to adapt normally to extrauterine life in the presence of a large pulmonary blood flow. In all four infant cases pulmonary arterial muscularity was increased in all parts of both lungs examined histologically, and in three, muscularity was significantly increased in arteries less than $300 \mu \mathrm{m}$ in diameter. It is these intra-acinar arteries which in the normal lung show the most rapid reduction in relative wall thickness after birth and which remain thick walled in experimental animals in which the pulmonary blood flow is doubled from birth. ${ }^{12}$ It is unclear, however, why the lung should fail to adapt normally in some but not in other cases of the scimitar syndrome. The presence of an interatrial shunt alone does not usually prevent adaptation from occurring normally, as in total anomalous pulmonary venous return without obstruction. It can be argued that interatrial shunting after birth is influenced by ventricular compliance and does not reach a maximum until the lungs have at least started to adapt normally to extrauterine life. ${ }^{13}$ The explanation of the presence of pulmonary hypertension in a minority of symptomatic infants with the scimitar syndrome could be that they have a larger systemic arterial flow to the lung, and a larger left to right shunt through a smaller total lung volume than do asymptomatic infants.

Operation for correction of anomalous pulmonary venous connection is usually recommended only when the left to right shunt exceeds $50 \% .{ }^{11}$ The four infants in the present series were ill because of the magnitude of the shunt. Two children had a right pneumonectomy and a third had a resection of part of the lower lobe supplied by systemic arteries and reimplantation of the anomalous vein into the left atrium. Though all these children withstood the operation, none ultimately survived. In the scimitar syndrome resection of lung tissue is usually carried out only in older patients in whom the affected part of the lung is chronically infected. In the small number of adults with a large left to right shunt blood is redirected from the right to the left atrium by detaching the anomalous vein from the inferior vena cava and reimplanting it into the left atrium. ${ }^{11}$

In young symptomatic children with the scimitar syndrome and a significant systemic arterial supply to a hypoplastic lung the abnormality is probably best corrected in two stages. At a first procedure the anomalous systemic arteries are ligated and at a second operation the large anomalous vein can be reimplanted into the left atrium with closure of an atrial septal defect if present. In adults with the scimitar syndrome an associated atrial septal defect is thought to be important in the pathogenesis of pulmonary hypertension. ${ }^{11}$ Since the part of the lung supplied by systemic arteries is also supplied by normal bronchial arteries the lung should not infarct provided that the bronchial arteries are not damaged during the dissection. An enlarged bronchial arterial supply will replace the systemic arterial supply in the lower part of the right 
lung. Though this lung tissue will be functionless under normal conditions, it is advisable not to resect tissue in a hypoplastic lung with abnormal lobation and poorly defined planes of cleavage.

\section{References}

1 Neill CA, Ferencz C, Sabiston DC, Sheldon H. The familial occurrence of hypoplastic right lung with systemic arterial supply and venous drainage "scimitar syndrome". Bulletin of the fohns Hopkins Hospital 1960; 107: $1-20$.

2 Kuiper-Oosterwal, Moulaert A. The scimitar syndrome in infancy and childhood. Eur f Cardiol 1973; 1: 55-61.

3 Mortensson W, Luindstrom NR. Broncho-pulmonary vascular malformation syndrome causing left heart failure during infancy. Acta Radiol [Diagn] (Stockh) 1971; 11: 449-58.

4 Park EA. Defective development of the right lung, due to anomalous development of the right pulmonary artery and vein, accompanied by dislocation of the heart simulating dextrocardia. Proceedings of the New York Pathological Society 1912; 12: 88-93.

5 Davies G, Reid L. Growth of the alveoli and pulmonary arteries in childhood. Thorax 1970; 25: 669-81.

6 Hislop A, Reid L. New pathological findings in emphysema of childhood. I Polyalveolar lobe with emphysema. Thorax 1970; 25: 682-90.

7 O'Rahilly R, Boyden EA. The timing and sequence of events in the development of the human respiratory system during the embryonic period proper. Zeitschrift fir Anatomie und Entwicklungsgeschichte 1973; 141: 237-50.

8 Congdon ED. Transformation of the aortic arch system during the development of the human embryo. Contributions to Embryology (Publications of the Camegie Institute) 1922; 14: 47-110.

9 Van Praagh R, Corsini I. Cor triatriatum: pathologic anatomy and a consideration of morphogenesis based on 13 postmortem cases and a study of normal development of the pulmonary vein and atrial septum in 83 human embryos. Am Heart $\mathcal{F}$ 1979; 78: 379-405.

10 Anderson RH, Ashley GT. Growth and development of the cardiovascular system-anatomical development. In: Davis JA, Dobbing J, eds. Scientific foundations of paediatrics. London: Heinemann, 1974: 165-98.

11 Honey M. Anomalous pulmonary venous drainage of right lung to inferior vena cava (scimitar syndrome): clinical spectrum in older patients and role of surgery. $\mathbf{Q F}$ Med 1977; 46: 463-83.

12 Haworth SG, de Leval M, Macartney FJ. Hypoperfusion and hyperperfusion in the immature lung. $\mathcal{F}$ Thorac $\mathrm{Car}$ diovasc Surg 1981; 82: 281-92.

13 Rudolph AM. Congenital diseases of the heart. Chicago: Year Book Medical Publishers, 1974.

Requests for reprints to Dr S G Haworth, The Hospital for Sick Children, Great Ormond Street, London WCIN 3JH. 